\title{
AVALIAÇÃO DO DESEMPENHO DE ALEVINOS DE Oreochromis niloticus (LINNAEUS, 1758) SUBMETIDOS A DIETA FRACIONADA
}

\author{
Iago Vinicios Geller* \\ Celine Campos** \\ Rafael Bueno Noleto**** \\ Marcos Otavio Ribeiro****
}

RESUMO: Atualmente o pescado é uma fonte proteica de alto valor econômico em nosso país, sendo a piscicultura uma alternativa economicamente viável para muitos produtores. A espécie Oreochromis niloticus (Tilápia do Nilo) apresenta desenvolvimento satisfatório em cultivos intensivos. Em sua produção as rações podem compor de $40 \%$ a $70 \%$ do custo total, sendo que seu crescimento será diretamente proporcional à taxa de arraçoamento estabelecida. O estudo objetivou avaliar o desempenho de alevinos de 0 . niloticus sob o efeito da dieta fracionada durante um período de 60 dias. Foram utilizados 225 alevinos de com peso médio de 3,5 gramas e tamanho médio de 5,5 centímetros, todos invertidos sexualmente a machos. Foram distribuídos 75 alevinos em cada unidade experimental, com capacidade de 10 metros cúbicos $\left(\mathrm{m}^{3}\right)$ totalizando três tratamentos, com três frequências alimentares distintas: uma alimentação ao dia com 5\% do peso vivo, duas alimentações ao dia com $5 \%$ do peso vivo e três alimentações ao dia com $5 \%$ do peso vivo, a quantidade foi a mesma, apenas fracionada, todos os tratamentos com a mesma ração comercial do tipo extrusada. Ao final dos 60 dias de experimento, os resultados do presente estudo demonstraram não haver diferenças significativas entre os tratamentos quanto ao crescimento de alevinos de tilápia submetidos a alimentação parcelada $(\mathrm{p}>0,05)$. Assim o produtor obtém resultados satisfatórios com parcela única quando comparados ao fornecimento parcelado em até três vezes ao dia.

PALAVRAS-CHAVE: Arraçoamento; Desempenho; Alevinos; Espécie exótica.

\footnotetext{
Licenciado em Ciências Biológicas pela Universidade Estadual do Paraná campus União da Vitória, Paraná, Brasil. E-mail: iagogeller@hotmail.com

** Licenciada em Ciências Biológicas pela Universidade Estadual do Paraná campus União da Vitória, Paraná, Brasil.

*** Doutor em Ciências Biológicas, docente permanente da Universidade Estadual do Paraná campus União da Vitória, Paraná, Brasil.

${ }^{* * * *}$ Mestre em Ciências Biológicas pela Universidade Estadual de Maringá. Docente temporário da Universidade Estadual do Paraná campus União da Vitória, Paraná, Brasil.
} 


\title{
PERFORMANCE OF Oreochromis niloticus (LINNAEUS, 1758) FRY WITH FRACTIONATED DIET
}

\begin{abstract}
Fish is a protein source with high economic value and fish farming is a viable alternative for many producers. Oreochromis niloticus (Nile tilapia) has a good development in intensive culture. Diet for breeding may comprise between 40 and $70 \%$ of total costs and fish growth is directly proportional to the established ration. Current study analyzes the performance of $O$. niloticus fry with fractionated diet during 60 days. Two hundred and twenty-five fry, mean weight $3.5 \mathrm{~g}$ and mean size $5.5 \mathrm{~cm}$, sexually male inverted, were employed. Seventy-five fry were distributed in each experimental unit $(10 \mathrm{~m} 3)$, with three treatments and three different feed frequencies: one daily feed comprising $5 \%$ of live weight; two daily feeds comprising $5 \%$ of live weight; three daily feeds comprising 5\% of live weight. Amount of diet was the same, albeit fractionated. All treatment had the same extruded commercial diet. Results after 60 days showed no significant differences between treatments for the growth of tilapia fry with fractionated diet $(p>0.05)$. The producer will have satisfactory results with a single diet when compared to feed distributed up to three times a day.
\end{abstract}

KEY WORDS: Ration; Performance; Fry; Exotic Species.

\section{INTRODUÇÃO}

O pescado é a carne com maior valor de mercado e com maior demanda mundial (SIDONIO et al., 2012). No Brasil, na última década, a piscicultura sofreu contínuas transformações, sendo o setor de carnes aquele que apresentou maior incremento percentual em produção (KUBITZA, 2015). Esse fator estabeleceu uma grande importância no agronegócio brasileiro (FIRETTI; GARCIA; SALES, 2007). O Brasil encontra-se entre os 14 maiores produtores mundiais de pescado, com uma produção de pouco mais de 562,5 mil toneladas, sendo $84,4 \%$ provenientes da piscicultura de água doce (FAO, 2016). No Estado do Paraná a produção chegou a 56 mil toneladas no mesmo período (EMATER, 2015).

A criação de espécies exóticas no Brasil mostra uma grande vantagem e facilidade em diferentes sistemas (GONZÁLEZ; QUEVEDO, 2001; ZIMMERMANN; FITZSIMMONS, 2004). Esses sistemas podem ser simples, como piscicultura familiar, 
ou até os que empregam alta tecnologia: aeradores, tanques-redes entre outros (SANTOS et al., 2009). Desta forma exibe alternativa econômica, principalmente para os pequenos produtores. Entretanto para obter os lucros esperados, devemse manejar métodos adequados e modernos baseados em princípios científicos, ecológicos, tecnológicos e econômicos (SABBAG et al., 2007).

Dentre as principais espécies exóticas cultivadas no país, a Tilápia do Nilo (Oreochromis. niloticus) destaca-se, exibindo versatilidade em seu desenvolvimento e adaptação a diversos ambientes (SANTOS et al., 2009). Seu crescimento é rápido apresentando resistência a doenças e suportando baixos teores de oxigênio dissolvidos na água (ONO; KUBITZA, 2003; NOGUEIRA, 2007; SANTOS et al., 2009). Além disso, demonstra ótima aceitação de rações além de aproveitar de forma eficiente o plâncton disponível, principalmente em baixa renovação de água (KUBITZA, 2006; BARBOSA; MOURA; SANTOS, 2010). Por se tratar de uma espécie oriunda de clima tropical, a tilápia apresenta ótima conversão alimentar na faixa de temperatura entre 25 e $30{ }^{\circ} \mathrm{C}$ (KUBITZA, 2000; CONTE; CYRINO, 2002; ONO; KUBITZA, 2003).

Contudo, o manejo alimentar influencia ainda no desempenho zootécnico dos animais, bem como custo ao produtor (FRASCA-SCORVO et al., 2007). Embora O. niloticus apresente diversas características favoráveis para seu cultivo, o custo de produção final apresenta-se alto para os produtores, dependendo diretamente do manejo alimentar utilizado. Ainda o excesso de ração pode levar à diminuição dos níveis de oxigênio dissolvido, em função do excesso de eutrofização, podendo causar a diminuição do crescimento e propensão a doenças e mortalidade do lote (FIOGBÉ; KESTMONT, 2003; MEURER et al., 2005). A ração comercial utilizada em pisciculturas comerciais é extrusada, a ração flutua por mais de 12 horas, entretanto, se permanecer na água por muito tempo, perde a palatabilidade, nutrientes, principalmente minerais e vitaminas, por lixiviação (TEIXEIRA et al., 2008). Estas rações podem compor de $40 \%$ a $70 \%$ do custo final do lote (KUBITZA, 1999; FERREIRA et al., 2007). Andrade et al. (2005) destacam que ração é o agente direcionador do custo variável de produção; em seu estudo apontam importante componente dos custos operacionais, ficando em média com 52,19\% do total do custo de produção. 
A dieta aplicada afeta diretamente o desenvolvimento dos alevinos, aumentando o tempo de cultivo para a obtenção do peso de mercado (CASTAGNOLLI, 1979; FIOGBÉ; KESTMONT, 2003; MEURER et al., 2005), sendo importante estabelecer uma estratégia de alimentação adequada para otimizar o crescimento e conversão alimentar dos alevinos, assim como diminuir a desigualdade final do lote (FERREIRA et al., 2007). Portanto, buscar alternativas para a redução do custo de produção se torna necessário para que o produtor obtenha um melhor custo benefício. Segundo Mihelakakis et al. (2002), o crescimento é diretamente proporcional à taxa de arraçoamento escolhida não acarretando em perda. Sendo assim, estabelecer a frequência ideal de arraçoamento para cada espécie é extremamente importante durante seu cultivo (KUBITZA, 1999; FERREIRA et al., 2007; SANTOS, 2014), para que o sistema de criação seja economicamente viável ao produtor.

Mediante ao exposto, o presente trabalho teve por objetivo avaliar o efeito da dieta fracionada sobre o crescimento de alevinos de $O$. Niloticus em frequências alimentares distintas buscando contribuir para o conhecimento do manejo alimentar desta espécie.

\section{MATERIAL E MÉTODOS}

O presente estudo foi realizado na estação de piscicultura da Universidade Estadual do Paraná - campus de União da Vitória (PR). Foram utilizados 225 alevinos de 0 . niloticus oriundos da própria estação de piscicultura de um lote padrão com peso médio de 3,5 gramas e tamanho médio de $5,5 \mathrm{~cm}$, sendo todos invertidos sexualmente a machos, pois em sistemas intensivos de cultivo o macho exibe performance de desenvolvimento superior que fêmeas. $\mathrm{O}$ experimento foi conduzido ao longo de 60 dias, durante os meses de dezembro, janeiro e fevereiro.

Os alevinos foram distribuídos em três tanques com capacidade de 10 metros cúbicos $\left(\mathrm{m}^{3}\right)$, sendo 75 alevinos para cada unidade, revestidos lateralmente de alvenaria, que receberam uma mistura de terra e areia no fundo localizado na parte externa. Os tanques ficam expostos ao tempo e são construções já existentes 
na estação. Os parâmetros físico-químicos da água analisados foram: temperatura $\left({ }^{\circ} \mathrm{C}\right)$ e oxigênio dissolvido $\left(\mathrm{mgL}^{-1}\right)$, que foram monitorados diariamente às $11 \mathrm{~h}$; potencial hidrogeniônico $(\mathrm{pH})$ e amônia $\left(\mathrm{NH}_{3}\right)$, monitorados a cada 15 dias. As taxas de arraçoamento nas unidades experimentais foram distribuídas em três grupos distintos (tratamentos), onde o fornecimento de ração (5\% do peso médio multiplicado pela quantidade de alevinos de cada tratamento) para os tratamentos foram iguais, sendo apenas parceladas as quantidades diárias de ração para cada tanque.

- Tanque 1 (T1): uma alimentação diária, às 08h;

- Tanque 2 (T2): duas alimentações diárias, às $08 \mathrm{~h}$ e 18h;

- Tanque 3 (T3): três alimentações, sendo a primeira às 08h, às $12 \mathrm{~h}$ e a última às $18 \mathrm{~h}$.

A quantidade de ração fornecida para os três tratamentos foi sendo reajustada conforme as biometrias a cada 15 dias, sendo $5 \%$ do peso vivo dos alevinos. Os alevinos das três unidades experimentais foram alimentados com a mesma ração comercial do tipo extrusada com 5 milímetros $(\mathrm{mm})$ de diâmetro seguindo as especificações do fabricante: $32 \%$ de proteína bruta (PB); umidade (máx.): 12\%; energia digestível: $3.500 \mathrm{Kcal} / \mathrm{kg}$; extrato etério (mín.): 7,0\%; cálcio (máx.): 2\%; fósforo (min): 1\%; vitamina C: $300 \mathrm{mg} / \mathrm{kg}$. Arraçoamento feito com rações extrusadas apresentam vantagem se comparado com as peletizadas, pois as extrusadas não decantam, assim o acompanhamento de seu consumo pode ser mais eficaz.

Para os primeiros 15 dias de tratamento, a ração foi macerada em um béquer para um melhor aproveitamento pelos alevinos. Após um período de aclimatação de 10 dias, e da biometria inicial, foram realizadas posteriormente mais outras três biometrias sendo a segunda 30 dias após o início do experimento, outra 45 dias e 60 dias com a biometria final. Foram retirados 10 alevinos de cada tratamento para esta pesagem. Ao final do período experimental todos os alevinos foram pesados em balança analítica de bancada e medidos individualmente em centímetros através de uma régua, para avaliação das variáveis de peso final total, comprimento final, conversão alimentar aparente e sobrevivência. Os dados obtidos das pesagens não 
atenderam os pressupostos de normalidade e homocedasticidade, e assim foram submetidos ao teste não paramétrico Kruskall-Wallis, através do programa Past considerando o nível de significância $\leq 0,05$.

A biomassa total (BT) foi calculada através da média total de cada pesagem, pelo número de indivíduos do tratamento. Ao fim do experimento todos os alevinos foram realocados em tanque de piscicultura da instituição, não havendo a necessidade de anestesia para as biometrias.

A relação peso-comprimento foi estimada utilizando a equação $P=a \cdot C b$, onde $P=$ peso total, $C=$ comprimento total, $a=$ intercepto e $b=$ coeficiente angular. Os parâmetros $a$ e $b$ foram estimados por regressão linear após transformação logarítmica dos dados de peso e comprimento. $O$ fator de condição alométrica foi estimado através de $K=P / C b$, sendo os parâmetros $P, C$ e $b$ definidos anteriormente. Foi analisado também o fator de condição alométrica relativa $K r=P r / P e$, sendo $P r o$ peso real e $P e$ o peso estimado pela equação $P=a \cdot C b$.

\section{RESULTADOS E DISCUSSÕES}

Os parâmetros físicos e químicos de qualidade da água não apresentaram alterações significativas se comparados com os padrões estabelecidos para o cultivo de $O$. niloticus em piscicultura, sendo a média da temperatura durante o período experimental da água de $25,7^{\circ} \mathrm{C}$. Segundo Hepheret et al. (1983), a faixa ótima de temperatura para o desenvolvimento de tilápias oscila entre 25 a $30{ }^{\circ} \mathrm{C}$, enquanto que para Lim (1989) e Kubitza (2000), $28{ }^{\circ} \mathrm{C}$ é considerada a temperatura ideal para a conversão alimentar desta espécie. A taxa de oxigênio dissolvido $(6,89 \mathrm{mgL}$ $\left.{ }^{1}\right)$, amônia $\left(0,121 \mathrm{NH}_{3}\right)$ e potencial hidrogeniônico $(8,5)$ estiveram dentro da faixa tolerável para cultivo de peixes em piscicultura preconizados por Boyd (1990) e Baldisserotto (2009). A taxa de sobrevivência para três tratamentos foi de $72 \%$.

Os resultados obtidos nas pesagens demonstraram não haver diferenças significativas entre os três tratamentos quanto ao crescimento de alevinos de $O$. niloticus submetidos a alimentação fracionada $(\mathrm{p}>0,05)$ apresentados nas Figuras 1 e 2 . 


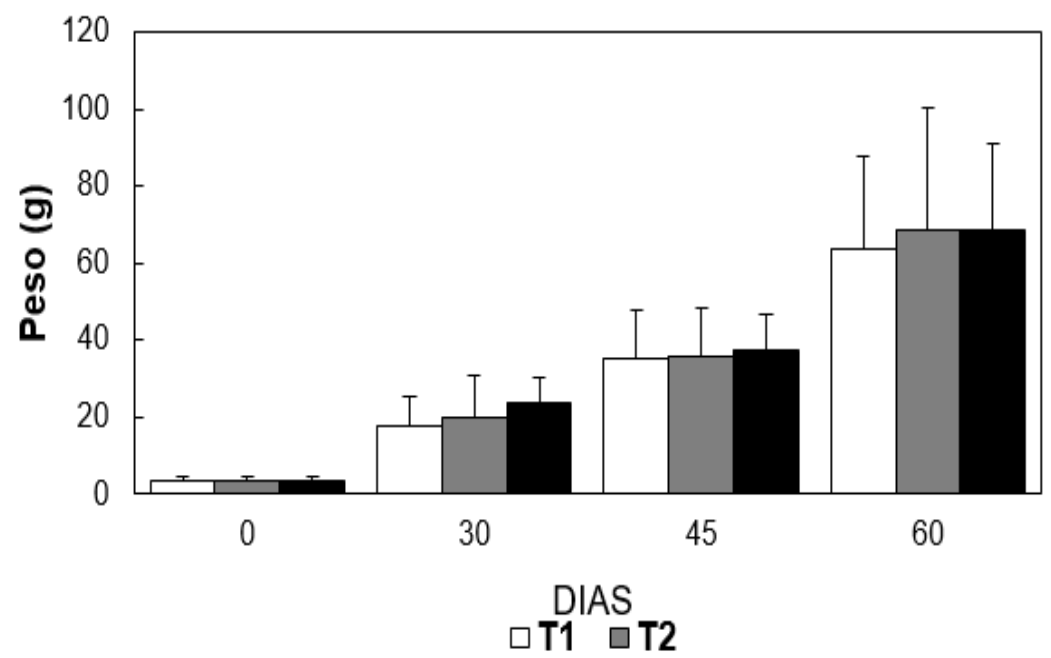

Figura 1. Média de ganho de peso e seus respectivos desvios padrões de alevinos de $O$. niloticus submetidos a três tipos de tratamento: (T1) alimentação uma vez ao dia; (T2) alimentação fracionada duas vezes ao dia; e (T3) alimentação fracionada três vezes ao dia.

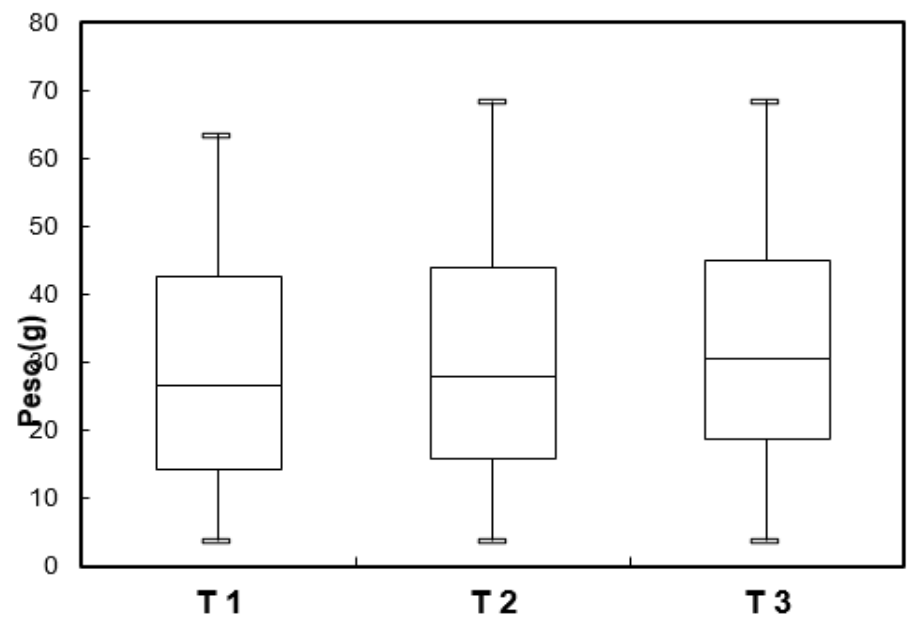

Figura 2. Tratamentos e suas respectivas variações de peso final em alevinos ao final de 60 dias. Os box representam a variação entre $25 \%$ e $75 \%$, seguida dos respectivos valores mínimo e máximo. A linha horizontal dentro de cada box representa a mediana. (T1) alimentação 1x ao dia; (T2) 2x ao dia; e (T3) 3x ao dia. 
Estudos realizados com tilápia em diversas fases de desenvolvimento têm exibido resultados distintos e similares ao encontrado no presente estudo para essa modalidade de tratamento. Marques et al. (2003) apontaram que a conversão alimentar dos alevinos de 0 . niloticus exibiu uma relação linear positiva em seu estudo, demonstrando que houve redução no aproveitamento da ração com o aumento do nível de arraçoamento, fato este confirmado pelas sobras de ração no tratamento onde foi testado o maior nível. Para Tung; Shiau (1991) foram encontrados melhor crescimento de alevinos de O. niloticus quando estes foram alimentados seis vezes ao dia. Sousa et al. (2012), em seu estudo com juvenis de tilápias em tanquesrede, verificaram que o melhor desempenho produtivo ocorreu quando alevinos eram alimentados a cada hora em comparação a alimentação de duas em duas horas. Oliveira et al. (2016), também com alevinos de tilápia, utilizando alimentação automatizada, verificaram que ração oferecida diariamente em alta frequência (48 refeições ao dia), a taxa de $4 \%$ do peso vivo proporcionou melhor ganho de peso em relação aos tratamentos com taxas de $2 \%$ e $3 \%$ do peso vivo, aumentando assim a frequência de alimentação sem desperdícios. Para Martineli (2017), que testou três frequências alimentares em tilápias da linhagem Supreme, sendo 2, 4 e 24 refeições/ dia, com alimentador automatizado, observou que os maiores valores de peso médio final e ganho médio de peso foram encontrados no tratamento de 24 refeições/dia.

Portanto, verifica-se que não existe um consenso quanto à taxa ideal de arraçoamento em $O$. niloticus quando levados em consideração fatores como: fase de desenvolvimento, sistema de cultivo e taxa de arraçoamento. Observamos que as estratégias adotadas de arraçoamento em alevinos de Tilápia podem ser adaptadas conforme a disponibilidade de recursos de mão de obra, infraestrutura e oferta de alimento. Porém mesmo não existindo um consenso, podemos apontar que o excesso de arraçoamento pode causar poluição precoce dos indicadores de qualidade de água. Todavia quando tratamos de larvicultura em $O$. niloticus observamos que a alimentação parcelada exibe melhores indicadores. Para Sanches; Hayashi (2001) em larvicultura é necessário alimentar as larvas de tilápia durante a reversão sexual, pelo menos quatro vezes espaçadas durante o dia, para melhorar seu desempenho.

Outros experimentos com espécies de interesse comercial para piscicultura têm demonstrado resultados interessantes quando submetidos à alimentação 
parcelada ou fracionada em sistemas de piscicultura. Para Carneiro e Mikos (2005), que trabalharam com alevinos de Rhamdia quelen (jundiá), apontam que não houve diferença significativa entre uma a quatro alimentações diárias. Ferreira et al. (2007), trabalhando com alevinos de Salminus brasiliensis (dourado), observaram que mesmo os alevinos que receberam a alimentação seis vezes ao dia, a conversão alimentar desse tratamento não refletiu na melhora do aproveitamento em seu peso final.

Por outro lado, existem estudos que encontraram correlação negativa, ou seja, o parcelamento da dieta influencia no crescimento e peso final, como em Astyanax bimaculatus (lambari do rabo-amarelo) (HAYASHI et al., 2004), com Ctenopharyngodon idella (carpa capim) (MARQUES et al., 2008), Cyprinus carpio (carpa comum) (BITTENCOURT et al., 2013) e Clarias gariepinus (catfish) (HOSSAIN; HAYLOR; BEVERIDGE, 2001), apresentando diferenças significativas em seu resultado final.

Os resultados do aumento em peso e comprimento são melhor explicados pelas equações de regressão linear (Tabela 1). O coeficiente alométrico representa uma ferramenta interessante para a piscicultura, pois fornece informações sobre o estado fisiológico dos peixes, uma vez que indivíduos com maior massa em um dado comprimento estão em melhor condição (VAZZOLER, 1996; LIMA-JUNIOR; CARDONE; GOITEIN, 2002). Para os três tratamentos o crescimento foi considerado isométrico ( $\mathrm{b}=3 ; \mathrm{p}<0,01)$, indicando que as taxas de crescimento do peso e do comprimento foram semelhantes; desta forma, o lote está homogêneo nos três tratamentos.

O fator de condição relativo mostrou um aumento na segunda pesagem (30 dias), seguido de um decréscimo na terceira e um leve aumento na última biometria (60 dias) (Figura 3), embora estatisticamente não significantes. 
Tabela 1. Equações de regressão linear

\begin{tabular}{c|c|c|c}
\hline Tratamento & Equação & $\mathrm{a}$ & $\mathrm{b}$ \\
\hline T1 & $\mathrm{P}=0,0198 \cdot \mathrm{C}^{2,985}$ & 0,0198 & 2,985 \\
T2 & $\mathrm{P}=0,0173 \cdot \mathrm{C}^{3,032}$ & 0,0173 & 3,032 \\
T3 & $\mathrm{P}=0,0231 \cdot \mathrm{C}^{2,906}$ & 0,0231 & 2,906 \\
\hline
\end{tabular}

Representação algébrica das curvas ajustadas da regressão $\mathrm{P}=\mathrm{a} \cdot \mathrm{C}^{\mathrm{b}}$ para os grupos de tilápia. $\mathrm{P}=$ peso total, $\mathrm{C}=$ comprimento total, (a) fator de condição relacionado com o grau de crescimento (peso e comprimento) e (b) fator de alometria. Fonte: Os Autores, 2017.
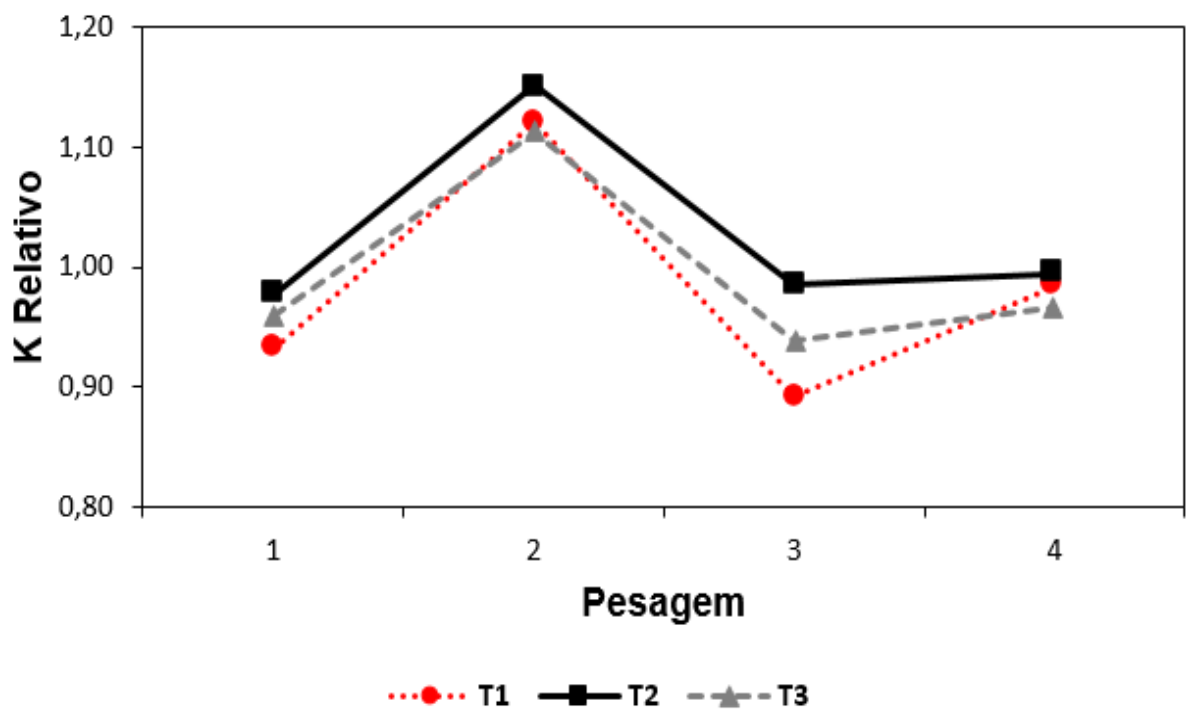

Figura 3. Fator de condição relativo em alevinos de tilápia em seus respectivos tratamentos. Ausência de diferenças significativas.

Os resultados de biomassa total para os três tratamentos durante o período experimental não apresentaram diferenças significativas $(\mathrm{p}>0,05)$ (Figura 4). Esse indicador reforça a hipótese que em alevinos de 0 . niloticus o fornecimento de alimentação parcelada não exibe resultados significativos, embora o gráfico demonstre uma pequena tendência em incremento de peso no tratamento de uma vez ao dia se comparado com os demais. 


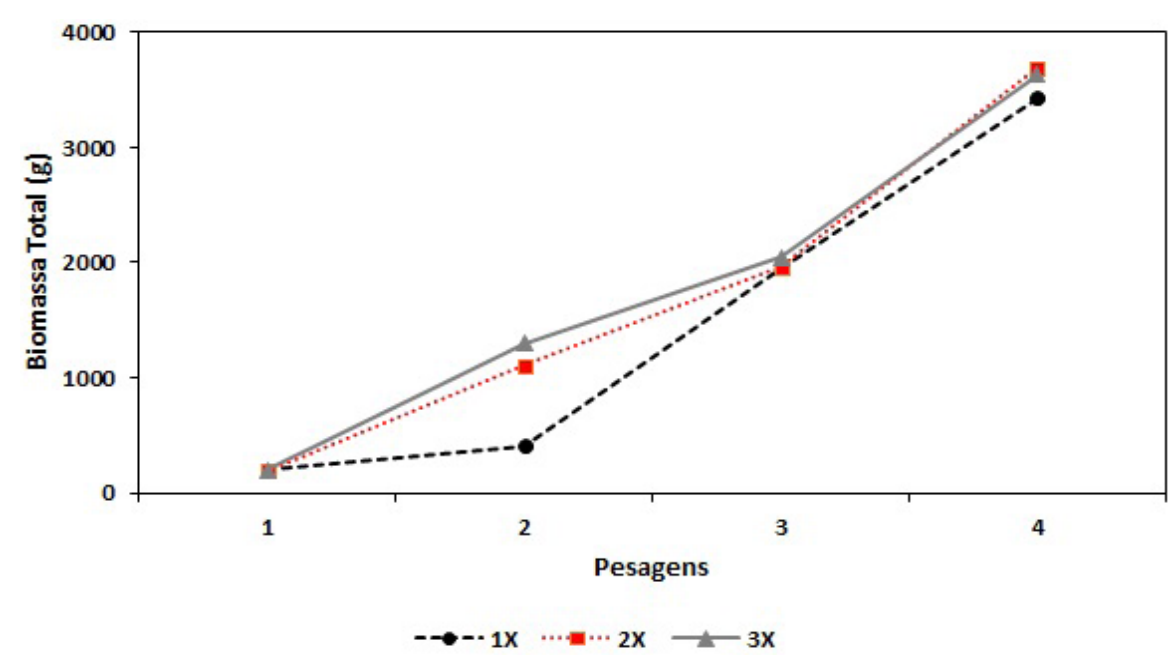

Figura 4. Biomassa total de alevinos de O. niloticus nos diferentes tratamentos. 1x (tratamento simples); $2 \mathrm{x}$ (tratamento duplo); 3x (tratamento triplo).

Os resultados do presente estudo indicaram que não houve diferenças significativas no que tange à dieta fracionada de uma, duas ou três ofertas de alimentação com 5\% do peso vivo em alevinos de tilápia em fase de crescimento inicial. Observamos também através desse e de outros trabalhos com tilápia, e outras espécies de interesse comercial em piscicultura, que fatores como fase de desenvolvimento, espécie, hábito alimentar, tipo de ração e quantidade de ração fornecida nesses sistemas podem influenciar no desenvolvimento dessas espécies. A maioria dos estudos observados com arraçomento de tilápia o mesmo é desenvolvido na fase adulta da espécie, desta forma estudos com alevinos são importantes, devido a maior perda do piscicultor ser na fase juvenil, devido à predação, queda de temperatura, doenças entre outros. 


\section{CONSIDERAÇÕES FINAIS}

Concluímos que durante os 60 dias de experimento, o fornecimento parcelado de ração na dieta de alevinos de tilápia entre peso médio de 3,60 g e $68 \mathrm{~g}$ não promoveu diferenças significativas em seu crescimento. Assim, o fornecimento de ração uma vez ao dia em alevinos de tilápia durante esta fase pode apresentar resultados similares quando comparados ao fornecimento parcelado em até três vezes ao dia. Portanto o piscicultor pode utilizar este método, possibilitando uma redução na mão de obra, facilitando o manejo diário e reduzindo os custos de mão de obra na produção.

\section{AGRADECIMENTOS}

À equipe do centro de piscicultura da UNESPAR - campus de União da Vitória (PR), pela oportunidade de desenvolver o trabalho em suas dependências.

\section{REFERÊNCIAS}

ANDRADE, R. L. B. de; WAGNER, R. L.; MAHL, I.; MARTINS, R. S. Custos de produção de tilápias (Oreochromis niloticus) em um modelo de propriedade da região oeste do Estado do Paraná, Brasil. Ciência Rural, Santa Maria, v. 35, n. 1, p. 198203, fev. 2005.

BALDISSEROTO, B. Fisiologia de peixes aplicada à piscicultura. 2. ed. UFSM: Santa Maria, 2009.

BARBOSA, A. C. A. B.; MOURA, E. V.; SANTOS, R. V. Cultivo de tilápia em gaiolas. Natal: EMPARN, v. 17. 2010.

BOYD, C. Water quality in ponds for aquaculture. Birmingham Publishing, Alambama, First Printing, 1990. p. 482. 
BITTENCOURT, F.; NEU, H. D.; POZZER, R.; LUI, T. A.; FEIDEN, A.; BOSCOLO, R. Frequência de arraçoamento para alevinos de carpa comum. Boletim do Instituto de Pesca, São Paulo, v. 2, n. 39, p. 149-156, mai, 2013.

CARNEIRO, P. C. F.; MIKOS, J. D. Frequência alimentar e crescimento de alevinos de jundiá, Rhamdia quelen. Ciência Rural, Santa Maria, v. 35, n. 1, p. 187-191, fev. 2005.

CASTAGNOLLI, N. Tecnologia de Alimentos de Peixes. In: FUNDAMENTOS de Nutrição de Peixes. São Paulo: Ceres, 1979.

CONTE, L.; CYRINO, J. E. P. Produtividade e economicidade da tilapicultura em gaiolas da região sudoeste do estado de São Paulo: estudo de casos. 2002. 73f. Dissertação (Mestrado) - Universidade de São Paulo, Piracicaba, 2002.

FAO. The State of world fisheries and aquaculture. Rome, 2016.

FERREIRA, R. A.; THIESEN, R.; COSTA, T. R.; BULGARELLI, A. L. A.; ISHIKAWA, M. M.; HISANO, H. Desempenho produtivo de alevinos de Dourado (Salminus brasiliensis) submetidos a diferentes frequências de alimentação. Ensaios e ciência, v. 11, n. 2, p. 33-38, 2007.

FIOGBÉ, E. D.; KESTMONT, P. Optimum daily ration for Eurasians perch Perca fluviatilis L. reared at its optimum growing temperature. Aquaculture, v. 216, p. 243-252, 2003.

FIRETTI, R.; GARCIA, S. M.; SALES, D. S. Planejamento estratégico e verificação de riscos na piscicultura. Pesquisa e Tecnologia, São Paulo, v. 4, n. 2, p. 1-10, jul. 2007.

FRASCA-SCORVO, C. M.; CARNEIRO, D. J.; MALHEIROS, E. B. Efeito do manejo alimentar no desempenho do matrinxã Brycon amazonicus em tanques de cultivo. Acta Amazônica, v. 37, n. 4, p. 621-628, 2007.

GONZÁLEZ, E.; QUEVEDO, T. Cultivo de las tilápias roja (Oreochromis spp.) y plateada (Oreochromis niloticus). Fundamentos de acuicultura continental, Bogotá, v. 21, p. 283-299, mar. 2014. 
HAYASHI, C.; MEURER, F.; BOSCOLO, W. R.; LACERDA, C. H. F.; KAVATA, B. C. L. Frequência de Arraçoamento para Alevinos de Lambari do Rabo-Amarelo (Astyanax bimaculatus). Revista Brasileira de Zootecnia, Maringá, v. 33, n. 1, p. 21-26, jun. 2004 .

HEPHER, B.; LIAO, I. C.; CHENG, S. H.; HSIEH, C. S. Food utilization by red tilapia - effects of diet composition, feeding level and temperature on utilization efficiencies for maintenance and growth. Aquaculture, Amsterdam, v. 32, p. 255-275, july. 1983.

HOSSAIN, M.; HAYLOR, G. S.; BEVERIDGE, M. C. M. Effect of feeding time and frequency on the growth and feed utilization of African catfish Clarias gariepinus (Burchell, 1822) fingerlings. Aquaculture Research, v. 32, p. 999-1004, 2001.

INSTITUTO PARANAENSE DE ASSISTÊNCIA TÉCNICA E EXTENSÃO RURAL - EMATER (Paraná) (org.). Projeto Piscicultura. 2015. Disponível em: http://www.emater.pr.gov.br/modules/conteudo/conteudo.php?conteudo=70. Acesso em: 23 set. 2017.

KUBITZA, F. Aquicultura no Brasil conquistas e desafios. Panorama de Aquicultura, São Paulo, v. 25, n. 150, p. 10-23, ago. 2015.

KUBITZA, F. Cultivo de Tilápias Dicas de ajuste na alimentação. Panorama de Aquicultura, São Paulo, v. 9, n. 52, p. 14-24, dez. 2006.

KUBITZA, F. Nutrição e Alimentação de Tilápia - Parte 1. Panorama de Aquicultura, São Paulo, v. 10, n. 59, p. 44-53, mai. 2000.

KUBITZA, F. Nutrição e Alimentação de Tilápia - Parte 1. Panorama de Aquicultura, São Paulo, v. 16, n. 98, p. 41-50, abr. 1999.

KUBITZA, F. Nutrição e Alimentação de Tilápia - Parte 2. Panorama de Aquicultura, São Paulo, v. 9, n. 53, p. 41-50, jun. 1999.

LIM, C. Pratical feeding-tilapias. Nutrition and Feeding of Fish, New York, v. 1, p. 163-183, jan. 1989. 
LIMA-JÚNIOR, S. E.; CARDONE, I. B.; GOITEIN, R. Determination of a method for calculation of allometric condition factor of fish. Acta Scientiarum, v. 24, n. 2, p. 397-400, 2002.

MARTINELI, G. M. Automação do fornecimento de ração e fracionamento da ração diária para tilápias criadas em ambiente controlado com dieta balanceada. 2017. 51f. Dissertação (Mestrado) - Universidade Estadual Paulista, Botucatu, São Paulo, 2017.

MARQUES, N. R.; HAYASHI, C.; SOARES, M. C.; SOARES, T. Níveis diários de arraçoamento para alevinos de tilápia do Nilo (Oreochromis niloticus) cultivados em baixas temperaturas. Semina, Londrina, v. 24, n. 1, p. 97-104, 2003.

MARQUES, N. R.; HAYASHI, C.; GALDIOLI, E. M.; SOARES, T.; FERNANDES, C. E. B. Frequência de alimentação diária para alevinos de carpa-capim (Ctenopharyngodon idella, V.), Boletim do Instituto de Pesca, São Paulo, v. 34, n. 2, p. 311-317, 2008.

MEURER, F.; HAYASHI, C.; BOSCOLO, W. R.; KAVATA, L. B.; LACERDA, C. H. F. Nível de Arraçoamento para Alevinos de Lambari-do-Rabo Amarelo (Astyanax bimaculatus). Revista Brasileira de Zootecnia, Viçosa, v. 34, n. 6, p. 1835-1840, dez, 2005.

MIHELAKAKIS, A.; TSOLKAS, C.; YOSHIMATSU, T. Optimization of feeding rate of hatchery-produced juvenile gilthead sea bream Sparus aurata. Journal of the World Aquaculture Society, v. 33, n. 2, p. 169-175, jun., 2002.

NOGUEIRA, A. C. Criação de tilápias em tanques rede. Salvador: SEBRAE, 2007. $23 \mathrm{p}$.

OLIVEIRA, F. A.; RGENTIM, P. K.; NOVELI, S. M. M.; AGOSTINHO, L. M.; AGOSTIN$\mathrm{HO}, \mathrm{C}$. A. Automatic feeders for Nile tilapia raised in cages: productive performance at high feeding frequencies and different rates. Arquivo Brasileiro de Medicina Veterinária e Zootecnia, Belo Horizonte, v. 68, n. 3, p. 702-708, 2016.

ONO, E. A.; KUBITZA, F. Cultivo de peixes em tanques-rede. 3. ed. Jundiaí: p. 112, 2003. 
SABBAG, O. J.; ROZALES, R. dos R.; TARSITANO, M. A. A.; SILVEIRA, A. N. Análise econômica da produção de tilápias (Oreochromis niloticus) em um modelo de propriedade associativista em Ilha Solteira/SP. Custo e Agronegócio, São Paulo, v. 3, n. 2, p. 86-100, dez. 2007.

SANCHES, L. E. F.; HAYASHI, C. Effect of feeding frequency on Nile tilapia, Oreochromis niloticus (L.) fries performance during sex reversal in hapas. Acta Scientiarum, Maringá, v. 23, n. 4, p. 871-876, jul. 2001.

SANTOS, E. L.; LUDKE, M. C. M. M.; RAMOS, A. M. P.; BARBOSA, J. M.; LUDKE, J. V.; RABELLO, C. B. V. Digestibilidade de subprodutos da mandioca para a Tilápia do Nilo. Revista Brasileira de Ciências Agrárias, Recife, v. 4, n. 3, p. 358-362, set. 2009.

SANTOS, E. L.; SANTOS, I. V. V. S.; LIRA, R. C.; SILVA, F. C.; MOURA, S. C. M.; FERREIRA, A. J. S.; SILVA, R. M. Frequência de arraçoamento para alevinos de Tilápia do Nilo (Oreochromis niloticus). Revista Agrotec, Alagoas, v. 35, n. 1, p. 171-177, 2014 .

SIDONIO, L.; CALVALCANTI, I.; CAPANEMA, L.; MORCH, R.; MAGALHÃES, G.; LIMA, J.; BURNS, V.; ALVES, J. A.; MUNGIOLI, R. Panorama da aquicultura no Brasil: desafios e oportunidades. BNDES Setorial Agroindústria, v. 35, p. 421-463, 2012.

SOUSA, R. M. R.; AGOSTINHO, C. A.; OLIVEIRA, F. A.; ARGENTIM, D.; NOVELLI, P. K.; AGOSTINHO, S. M. M. Productive performance of Nile tilapia (Oreochromis niloticus) fed at different frequencies and periods with automatic dispenser. Arquivo Brasileiro de Medicina Veterinária e Zootecnia, v. 64, p. 192-197, 2012.

TEIXEIRA, E. A.; CREPALDI, D. V.; FARIA, P. M. C.; RIBEIRO, L. P.; MELO, D. C.; EULER, A. C. C. Revista Brasileira Saúde Produção Animal, v. 9, n. 2, p. 239-246, abr./jun., 2008.

TUNG, P.-H.; SHIAU, S.-Y. Effects of meal frequency on growth performance of hybrid tilapia, Oreochromis niloticus $\mathrm{O}$. aureus, fed different carbohydrate diets. Aquaculture, v. 92, p. 343-350, 1991. 
VAZZOLER, A. E. A. de M. Biologia da reprodução de peixes teleósteos: teoria e prática. Maringá: EDUEM, 1996.

ZIMMERMANN, S.; FITZSIMMONS, K. Tilapicultura intensive. In: CYRINO, J. E. P.; URBINATI, E. C.; FRACALOSI, D. M.; CASTAGNOLLI, N. (ed.). Tópicos especiais em piscicultura de água doce tropical intensiva: São Paulo: TecArt, Cap. 9, p. 239-266, 2004.

Recebido em: 01/02/2018

Aceito em: 24/05/2018 